\title{
A case study of COVID-19 in the Arab Middle East and North Africa with a focus on Jordan during the year 2020
}

\section{Abstract}

During the last year (2020) the Coronavirus disease 2019 (COVID-2019) has been recognized as a global threat affected 181 countries with approximately 83 million confirmed cases and 1.8 million death, accordingly Transmission of the infection has rapidly increased in Arab Middle East and North Africa (MENA) as well as in Jordan, living behind a huge number of infected cases and deaths. During this situation an analysis of the spread of the disease must be recognized. For the analysis of the impact of the disease in the population during this time period, epidemiological indexes have been introduced

The novel coronavirus (COVID-19) has sickened millions of people, lock down major cities and some countries, prompted unprecedented global travel restrictions. Real data-driven modeling is an effort to help evaluate and curb the spread of the novel virus. This Work aims to provide a model by using cumulative cases for Coronavirus disease outbreak in most major countries with focusing on the Jordanian experience and response in combating COVID-19.

On March $2^{\text {nd }}, 2020$, Jordan reported the first confirmed cases of COVID-19. Although, Jordan was among the first countries to implement highly strict preventive and control measures, the outbreak started around $1^{\text {st }}$ October, 2020 (7 months later), after that there was a significant increase in the number of confirmed cases, In this work we focus on the evolution of the COVID-19 in Jordan and to answer the question "Do the policies of social isolation really work? However, there are always opportunities to learn from the global experience to improve the current national strategy.

\section{Keywords}

Biostatistics; Bioinformatics; Coronavirus; Data Processing; Epidemiology; Arab Countries; Jordan.
Maen A. Addassi ${ }^{1}$

1 Free researcher, Amman, Jordan.

Contact information:

Pharmacist Maen A. Addassi.

”maenaddassi@yahoo.com

Received 15-03-2021; Accepted 13-05-2021 


\section{Introduction}

The COVID-19 outbreak (previously 2019-nCoV) was caused by the SARS-CoV-2 virus. This outbreak started in December 2019 in Wuhan city in Hubei province of China. COVID-19 continued to spread across the world, leading to a global pandemic [1].

The median incubation period of COVID-19 is 5-6 days, ranging from 1 to 14 days. [2] The infectious period remains uncertain; however, it has recently been estimated to be from 48 hours before symptoms develop until two weeks from symptom's onset $[2,3]$.

In majority of cases patients recover from the disease without clinical intervention; however, approximately $20 \%$ of global cases resulted in more severe outcomes, such as shortness of breath and pneumonia, [4] necessitating hospitalization and the requiring additional oxygen or ventilation. (4.5) Severe or fatal outcomes are generally more common among elderly cases or those with co-morbid conditions [4].

The epidemiology of COVID-19 in Jordan has continued to evolve since cases were first detected in the country on March 2, 2020. This paper provides an overview of the Jordanian COVID-19 epidemic, and compiles data from a variety of sources to describe cases and clusters, testing patterns, and the international situation.

Epidemiological analysis of the outbreak was quickly used to start estimating epidemiologically relevant parameters, such as the basic reproduction number, the serial interval, the incubation period and the case fatality rate [6]. Initial estimates suggested the case fatality rate was less than $4 \%$ [7]. Control of spread by contact tracing and isolation appears to be challenging, given what is currently known about the virus [7].

\section{Methods and Basic Statistics}

We used open-domain data on COVID-19 reported cases and deaths per country per day. The data were obtained from the World Health Organization, the Worldometer [3-5] and The Official Jordanian reports issued by Ministry of Health $[8,9,10] \mathrm{A}$ subset of 18 countries was analyzed.

During 2020, in MENA, 3.230 Million new cases have been recorded, 55,670 new deaths Prevalence $(P)$ is defined as the number of persons with a disease or unhealthy condition in a particular period in the general population. Based on that definition during the previous period, the prevalence $(P)$ for the infected patients in MENA is (3.230 Million/416.7 Million) $100 \%=0.78 \%$. The full detailed prevalence per country will be discussed later.

\section{Data Analysis}

In this paper, the relations are assumed to be match with the common Epidemic (Epi) Curve which is Continuous common source epidemics

\section{Coronavirus pandemic}

On $23^{\text {rd }}$ January 2020, in Wuhan- Hubei Province of the People's Republic of China (PRC) became the first city to implement a lockdown featuring strict restrictions on the movement of people as a tool for suppressing the spread of the novel coronavirus disease, COVID-19 [1].

The terms "lockdown" or "shutdown" are being used by many to describe relatively general and widespread restrictions on movement, work, and travel on people in a city, region, or country. They can be distinguished from quarantines, which involve separating and restricting people who have been exposed to a disease, such as COVID-19.

Since then, lockdowns of varying stringency and duration- Together with other types of non-pharmaceutical interventions such as mandates to wear masks and efforts to test, trace, and isolate individuals potentially exposed to COVID-19- have been implemented in many countries. 
The pandemic of the novel coronavirus SARSCoV-2 has caused 83.05 million confirmed cases and 1.81 million deaths as of $31^{\text {st }}$ December 2020 [8].

As a precautionary measure, or in response to locally detected outbreaks, countries have introduced control measures with varying degrees of stringency [1], including isolation and quarantine, school, and workplace closures; bans on social gatherings, physical distancing, and masks; and stay-at-home orders.

\section{Monitoring and tracking the disease}

As the virus that causes COVID-19 began to spread from person to person in communities (community transmission), scientists needed to track the disease and tried to slow its spread. To do so, they needed a common definition for a case of COVID-19. Having a case definition helps to make sure cases are counted the same way everywhere. In the United States, according to The Centers for Disease Control and Prevention (CDC), a confirmed case of COVID-19 is defined as a person who tests positive for the virus that causes COVID-19 [9].

As cases of COVID-19 are being reported, epidemiologists are conducting public health surveillance, i.e., the systematic collection, analysis, and interpretation of health data. Surveillance allows epidemiologists to calculate:

- Incidence (number of new cases reported over a specific period of time).

- Prevalence (number of cases at one specific point in time).

- Hospitalizations (number of cases resulting in hospitalization).

- Deaths (number of cases resulting in death).

Which leads to building up an "An epidemic curve". This shows the frequency of new cases over time based on the date of onset of disease. The shape of the curve in relation to the incubation period for a particular disease can give clues about the source [11]

\section{What is an Epidemic (Epi) Curve?}

An epidemic curve, also known as an epi curve or epidemiological curve, is a statistical chart used to visualize the onset and progression of a disease outbreak. [12] Epi curves typically display a graph of the onset of illness among cases in an outbreak.

- Horizontal $x$-axis shows the dates of illness onset among cases.

- Vertical y-axis shows the number of cases.

For the COVID-19 outbreak, major agencies display cases differently:

- World Health Organization (WHO) show graphs based on the date of case reporting [13].

- US Center for Disease Control (CDC) display cases by onset of illness. For COVID-19, the CDC has also started to report cumulative cases based on date of reporting $[12,13]$.

There are three basic types of epidemic curve [14].

- Point source outbreaks (epidemics) tends to have epidemic curves with a rapid increase in cases followed by a somewhat slower decline, and all the cases tend to fall within one incubation period. (Figure 1)

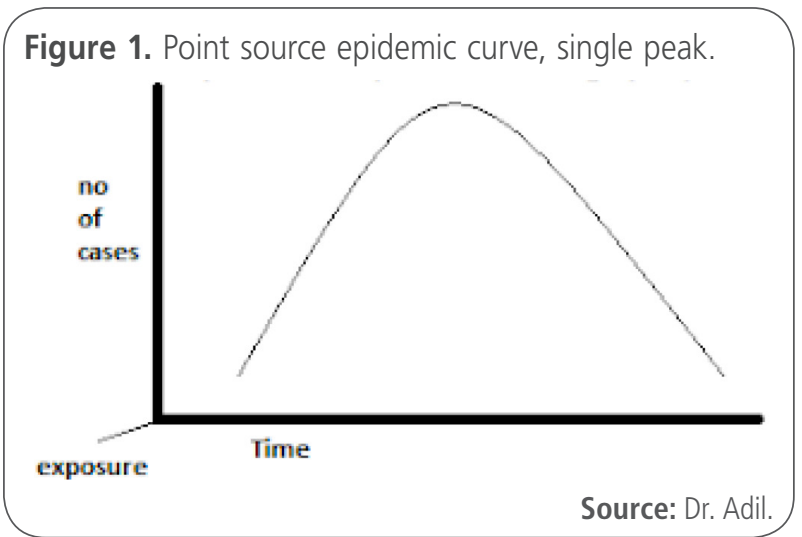

- Continuous common source epidemics Common source, continuous or repeated exposu-

re. In this case, epidemic reaches a sharp peak but tails off gradually over a longer period of 
time, although the sharp peak is attained after a longer time than a point source epidemic [11]. (Figure 2)

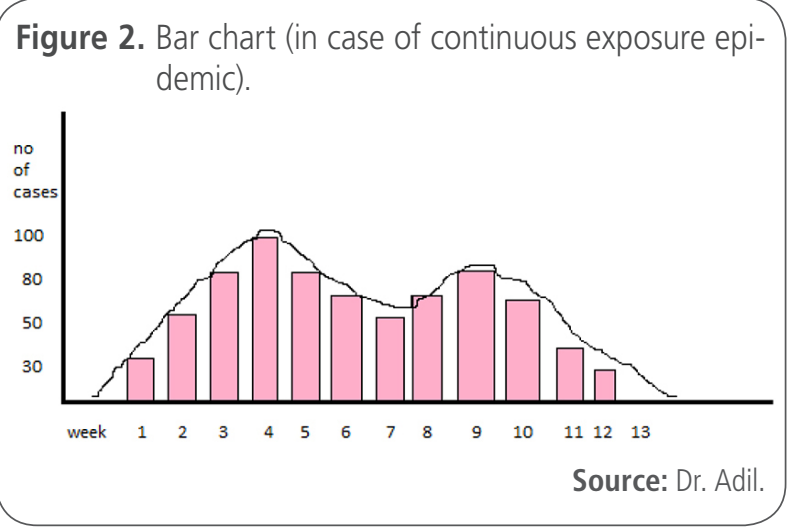

- Propagated (or progressive source) epidemic curve. An infected person can transfer the infection to another healthy person and make him infectious as well and then he can further transmit the infection to other people by various means (direct contact, sexual contact, through vectors, etc.). The epidemic stays in the community if susceptible and unimmunized individuals remains present. (Figure 3)

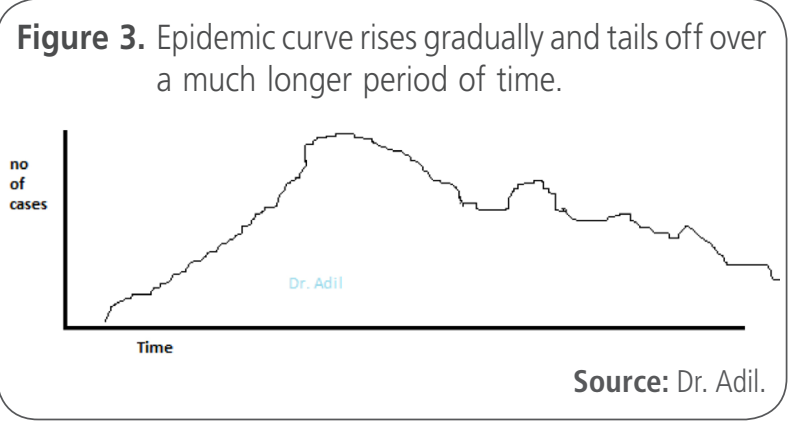

The epidemic starts to terminate when the number of susceptible individuals decreases, or people develop immunity against the disease. Herd immunity plays a special role in this case. The epidemic curve shows a gradual rise and tails of over a much longer time as compared to common source repeated exposure epidemic $[12,13$, 14].

\section{Flattening the COVID-19 Epidemic Curve}

Without speedy and coordinated public health actions such as rapid testing, isolation of cases, "social distancing" and stay-at -home policies, the number of COVID-19 cases could rise beyond the capacity of the healthcare system to handle severe cases. The goal is to "flatten" means to reduce the daily rate of new cases so that the number of severe cases can be handled effectively by the healthcare system. Note that public health actions taken to "flatten the curve" do not guarantee the reduction in total number of cases during a pandemic. That will be determined by additional factors such the speed by which other effective prevention measures (e.g., vaccines) are developed. Flatten the curve is illustrated in the schematic of Figure $\mathbf{4}(\mathbf{a}, \mathbf{b})$ by comparing two idealized epidemic trajectories: one with interventions and one without interventions.

Figure 4: Epidemic trajectory without intervention; a) Short and kurtose curve; b) Flat and stretched curve.

a)

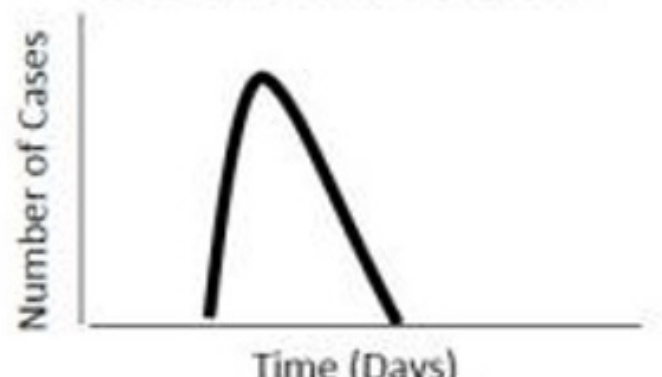

b)

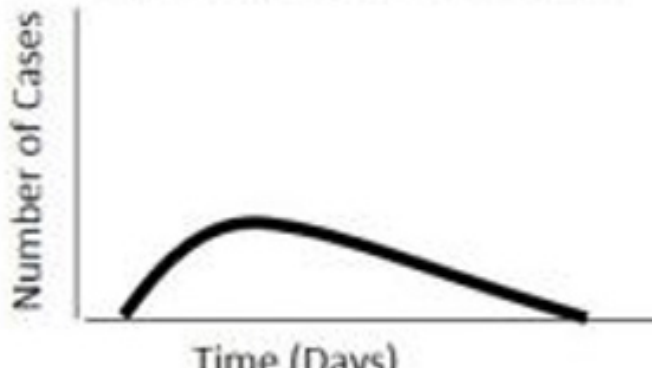

Source: Dr. Abil.

General features of global epidemic curves $[8,9]$

In Figures $5 \& 6$. 
Figure 5: The weekly global new cases and cumulative cases from Jan 1st, 2020 to Dec. 315t, 2020.



Figure 6: The weekly global deaths and cumulative deaths from Jan 1st, 2020 to Dec. 315t, 2020.

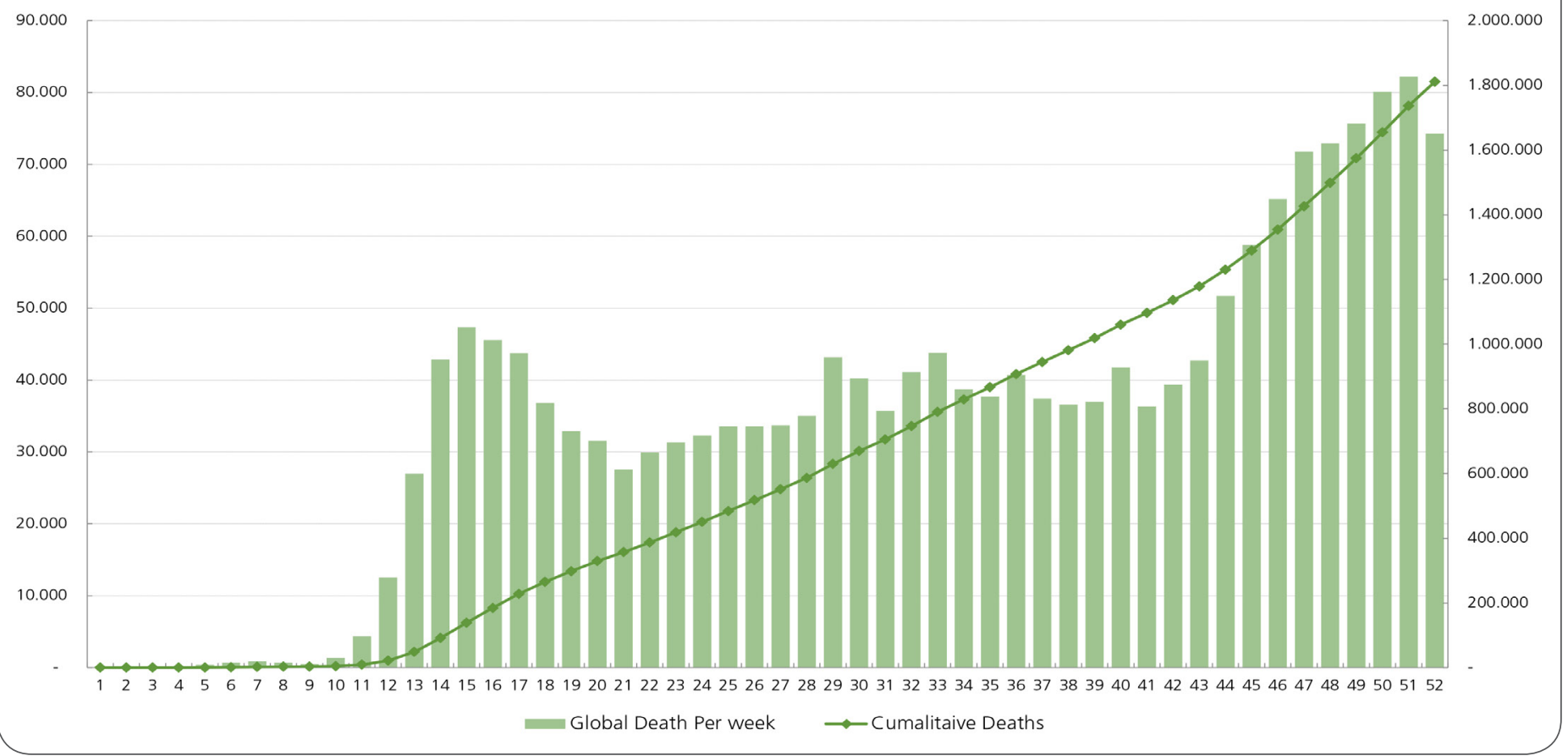


The novel coronavirus (COVID-19) pandemic in the Arab countries in the Middle East and North Africa [15]

The novel coronavirus (COVID-19) pandemic has affected the countries in the Middle East and North Africa (MENA) region in different ways. Varying political structures, economic conditions, and civilcrisis preparedness of the states in this region have resulted in it being handled in a variety of ways too. Even if it is difficult to assess how the crisis has affected the MENA region in more detail due to the region's general volatility and ongoing conflicts in Libya, Yemen and Syria, current trends have so far not shown a diminution in regional conflicts.

To the End of 2020, Middle East and North Africa registered $\sim 3.230$ Million cases, distributed as the below Figure 7.

Figure 7: Total cumulative cases in the Middle East and North Africa from Jan 15t, 2020 to Dec. 315t, 2020.



The Tables $1 \& \mathbf{2}$ and Figures $\mathbf{8}, \mathbf{9} \& \mathbf{1 0}$ are an overview of the novel coronavirus (COVID-19) pandemic in the Arab Middle East and North Africa countries [8].

\section{Epidemic (Epi) Curve for some Arab countries $[8,9]$}

Figures 11-17 show the weekly confirmed new cases and cumulative cases' trend for COVID-19 from $1^{\text {st }}$ January to $31^{\text {st }}$ December 2020 for some Arab countries

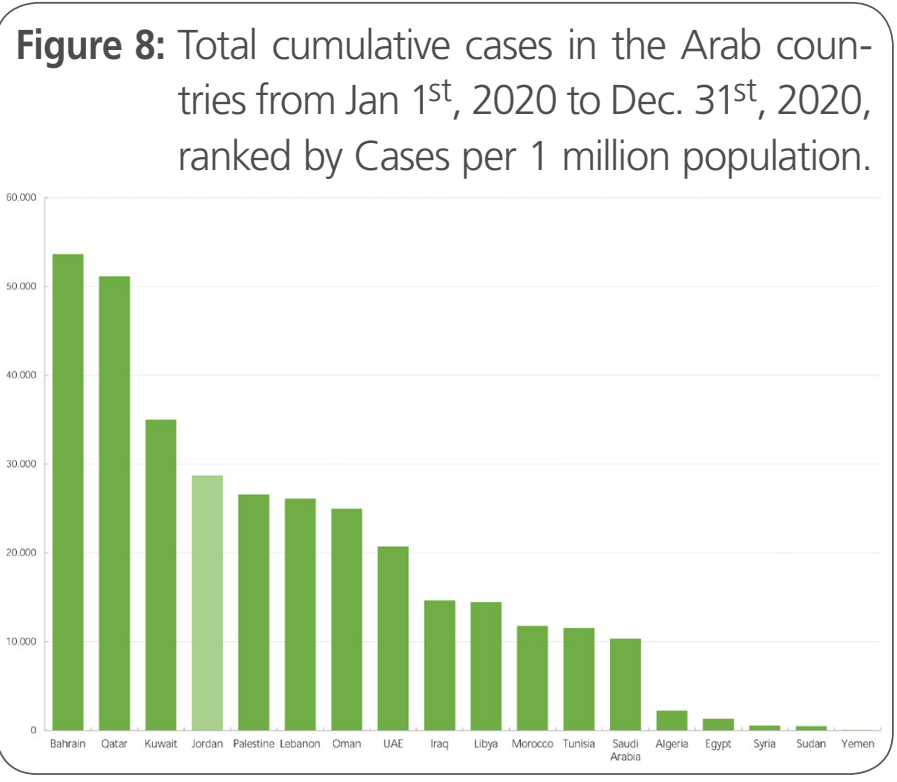

Figure 9: Total cumulative deaths in the Arab countries from Jan $1^{\text {st }}, 2020$ to Dec. $31^{\text {st }}, 2020$, ranked by Death per 1 million population.

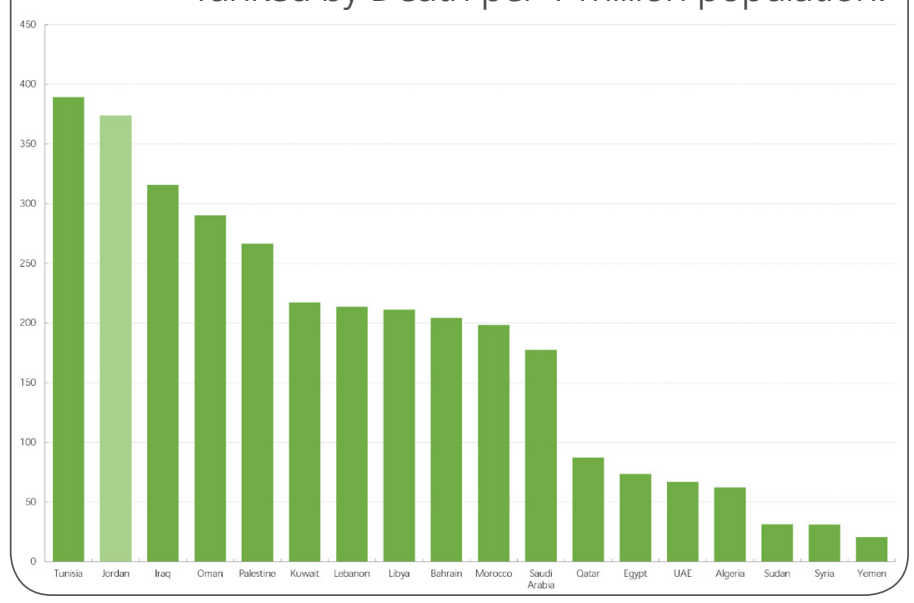

Figure 10: Prevalence percentage in the Arab countries from Jan $1^{\text {st }}, 2020$ to Dec. $31^{\text {st }}$, 2020.

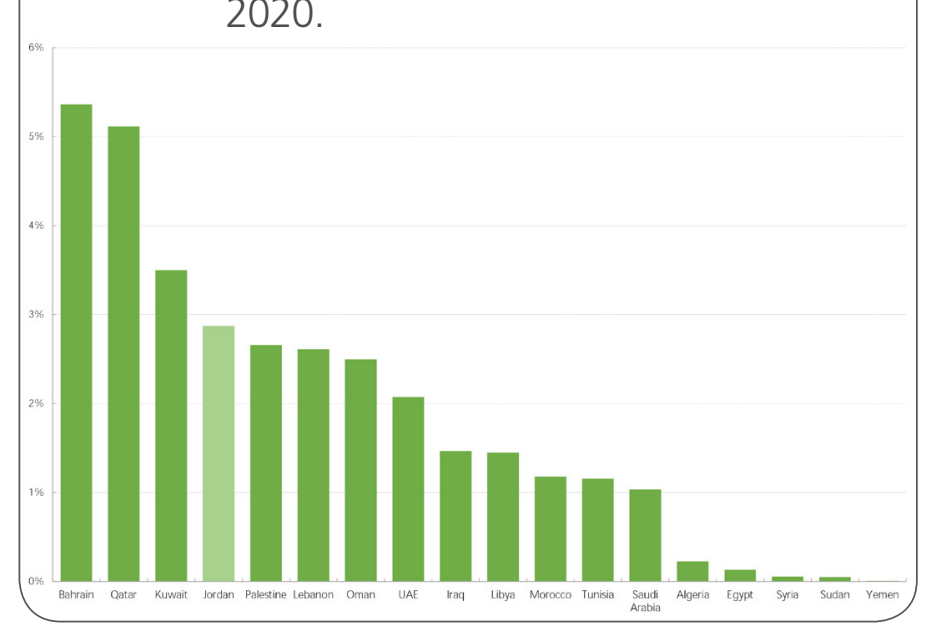


Table 1. Total cumulative cases in the Arab countries from Jan $1^{\text {st }}, 2020$ to Dec. 31 $1^{\text {st }}, 2020$, ranked by Cases per 1 million population.
Table 2. Total cumulative deaths in the Arab countries from Jan 1st ,2020 to Dec. 31st, 2020, ranked by Death per 1 million population.

\begin{tabular}{|c|c|c|c|c|c|c|c|}
\hline No. & Country, & Total Cases & Cases/M & No. & Country, & Total Deaths & Deaths/M \\
\hline 1 & Bahrain & 92,425 & 53,629 & 1 & Tunisia & 4,620 & 389 \\
\hline 2 & Qatar & 143,621 & 51,151 & 2 & Jordan & 3,815 & 374 \\
\hline 3 & Kuwait & 150,298 & 34,998 & 3 & Iraq & 12,808 & 316 \\
\hline 4 & Jordan & 293,067 & 28,732 & 4 & Oman & 1,497 & 290 \\
\hline 5 & Palestine & 136,736 & 26,572 & 5 & Palestine & 1371 & 266 \\
\hline 6 & Lebanon & 177,996 & 26,123 & 6 & Kuwait & 933 & 217 \\
\hline 7 & Oman & 128,719 & 24,969 & 7 & Lebanon & 1456 & 214 \\
\hline 8 & UAE & 206,092 & 20,743 & 8 & Libya & 1,459 & 211 \\
\hline 9 & Iraq & 594,442 & 14,656 & 9 & Bahrain & 352 & 204 \\
\hline 10 & Libya & 99,935 & 14,469 & 10 & Morocco & 7,355 & 198 \\
\hline 11 & Morocco & 437,332 & 11,795 & 11 & Saudi Arabia & 6,214 & 177 \\
\hline 12 & Tunisia & 137,216 & 11,564 & 12 & Qatar & 245 & 87 \\
\hline 13 & Saudi Arabia & 362,601 & 10,355 & 13 & Egypt & 7,576 & 74 \\
\hline 14 & Algeria & 99,311 & 2,249 & 14 & UAE & 665 & 67 \\
\hline 15 & Egypt & 136,644 & 1,326 & 15 & Algeria & 2,751 & 62 \\
\hline 16 & Syria & 9,603 & 544 & 16 & Sudan & 1,384 & 31 \\
\hline 17 & Sudan & 22,082 & 499 & 17 & Syria & 551 & 31 \\
\hline 18 & Yemen & 2,191 & 73 & 18 & Yemen & 619 & 21 \\
\hline
\end{tabular}

Figure 11. The weekly Saudi Arabia new cases and cumulative cases from Jan 1st, 2020 to Dec. 315t, 2020.




Figure 12: The weekly United Arabia Emirates new cases and cumulative cases from Jan 1st, 2020 to Dec. $31^{\text {st }}, 2020$.



Figure 13: The weekly Qatar new cases and cumulative cases from Jan 1st, 2020 to Dec. 315t, 2020.

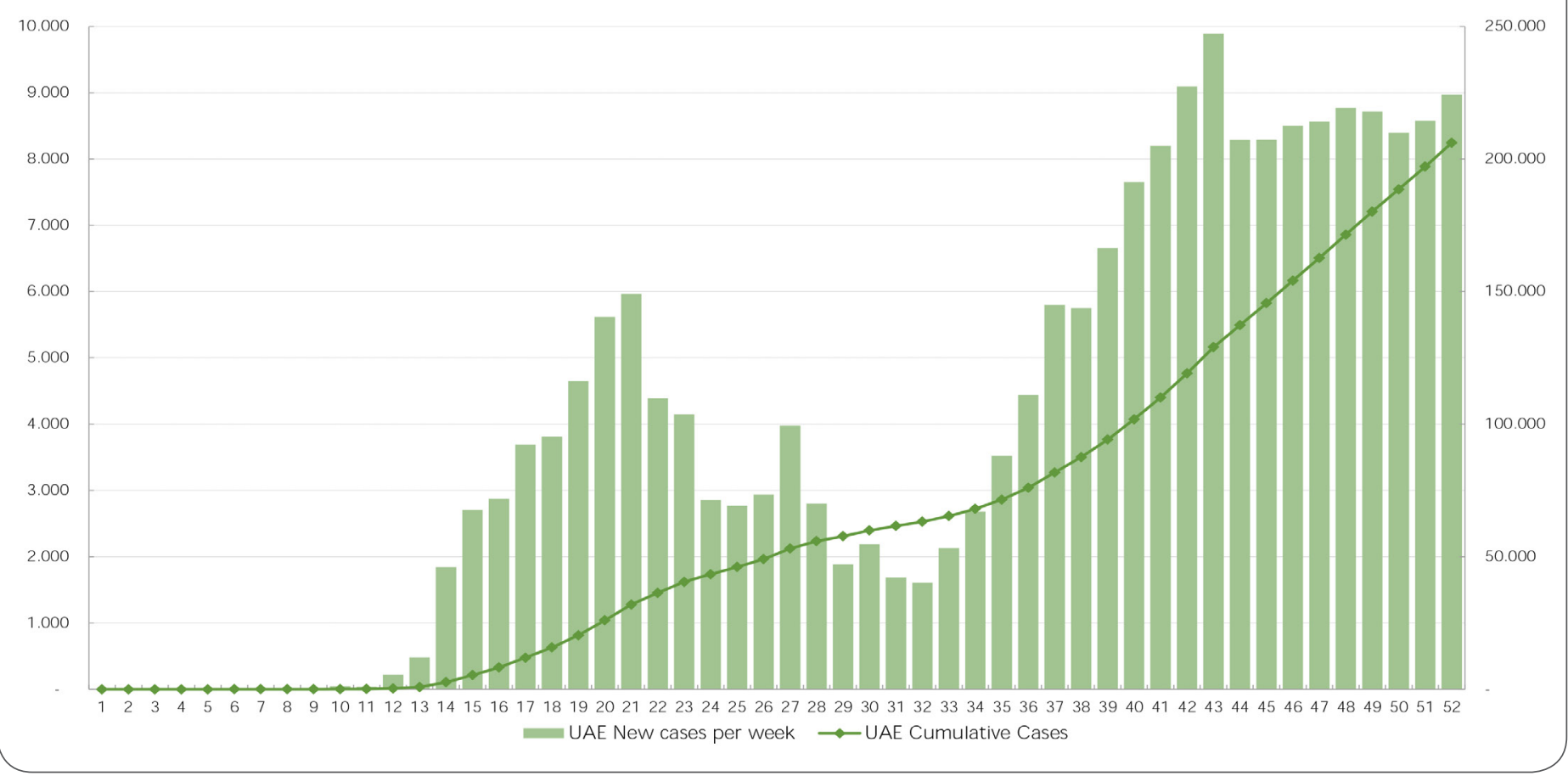


Figure 14: The weekly Kuwait new cases and cumulative cases from Jan 15t, 2020 to Dec. 31st, 2020.

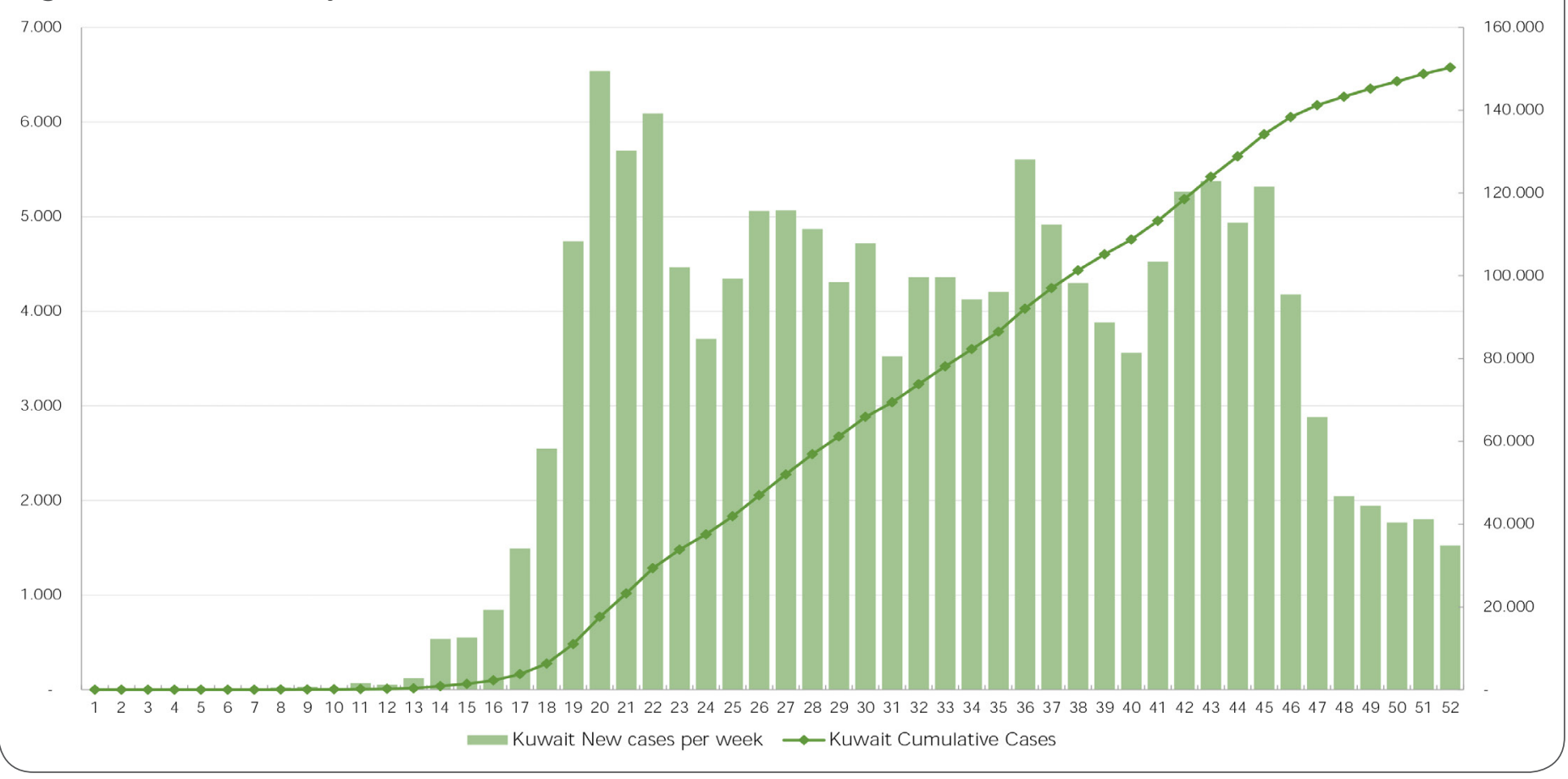

Figure 15: The weekly Egypt new cases and cumulative cases from Jan 1st, 2020 to Dec. 31st, 2020.

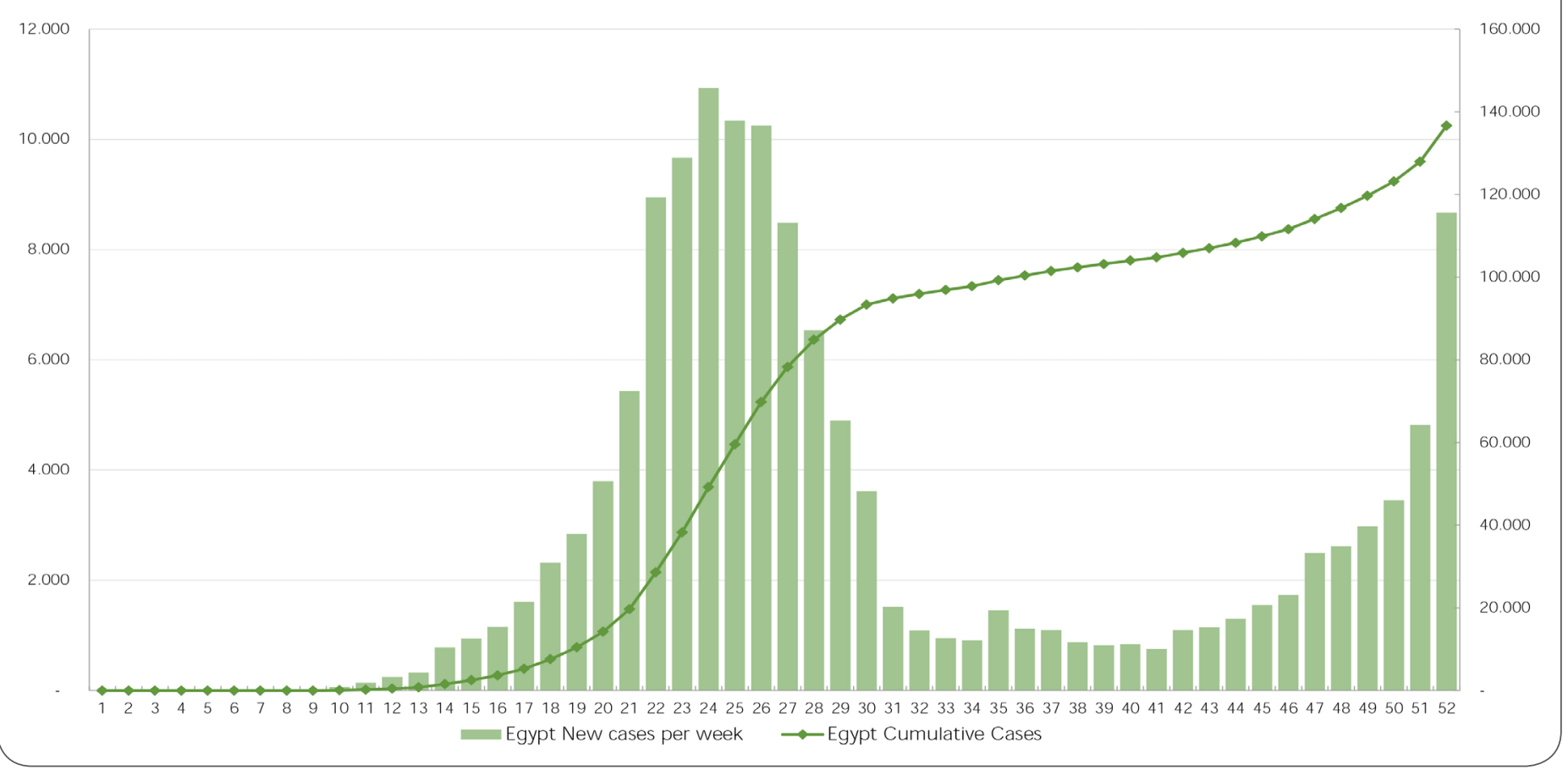


Figure 16: The weekly Iraq new cases and cumulative cases from Jan 15t, 2020 to Dec. 315t, 2020.

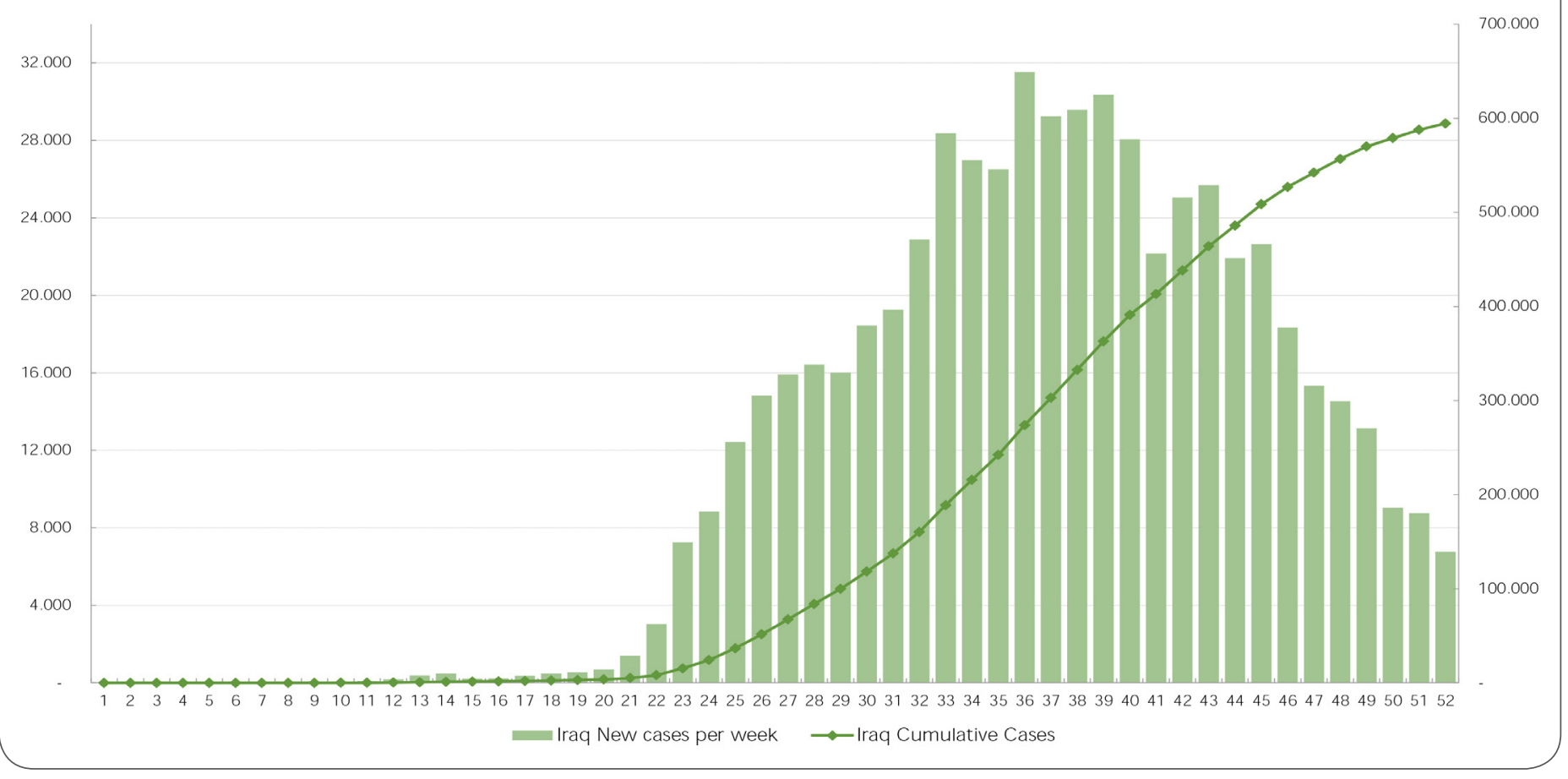

Figure 17: The weekly Palestine new cases and cumulative cases from Jan 115t, 2020 to Dec. 315t, 2020.

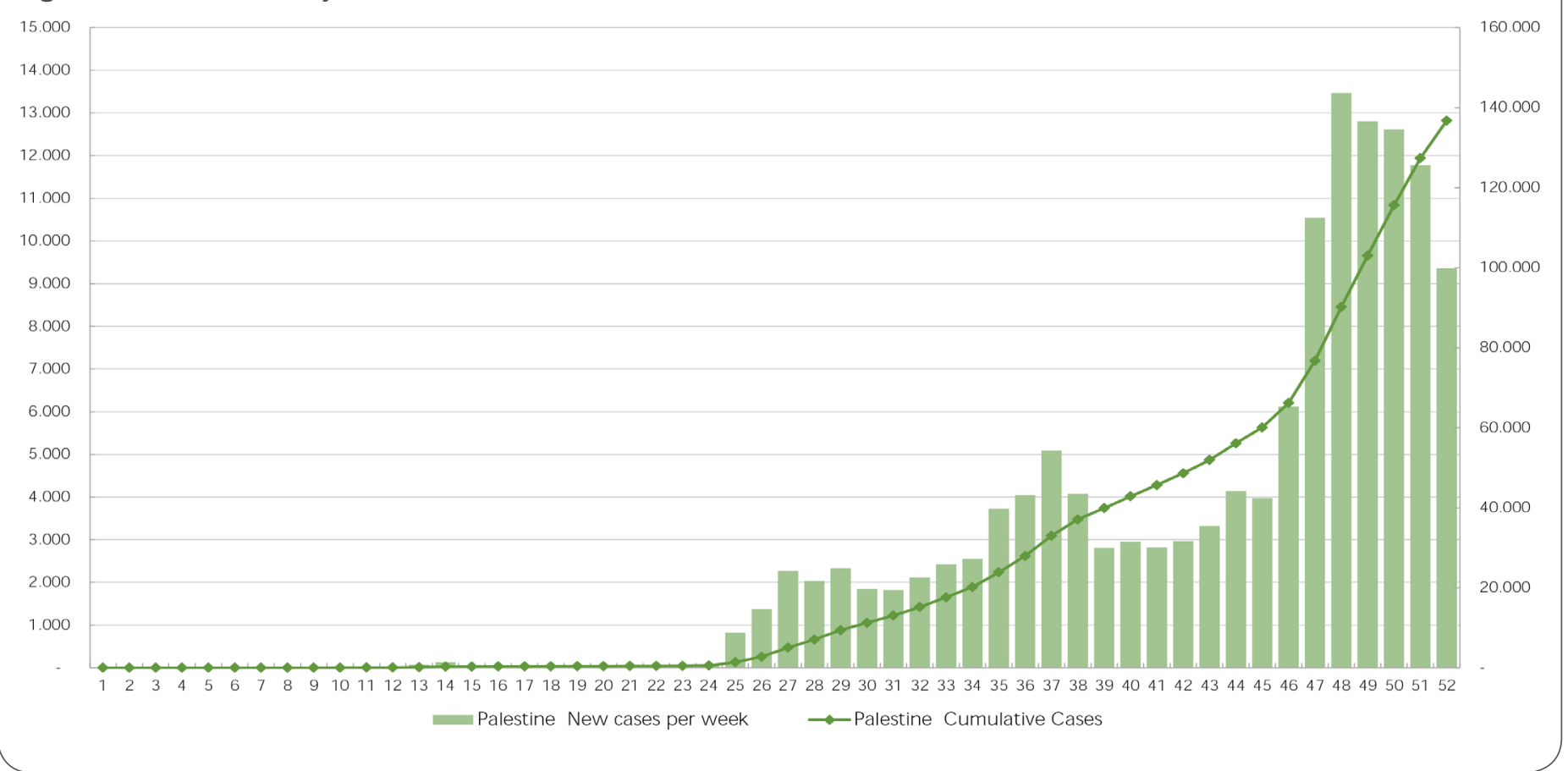




\section{Jordan and COVID-19}

The Hashemite Kingdom of Jordan is located in the Eastern Mediterranean region with an estimated population of around 10.6 million (17). Jordan shares borders with Iraq, Israel and the occupied Palestinian territory, Saudi Arabia, and Syria [17].

\section{Background}

Jordan has reported 293,067 cumulative cases, and 3,815 deaths related to COVID as of December $31^{\text {st }}, 2020$. At the onset of the global epidemic, the authorities implemented a range of measures to try and limit the spread of the virus. Two weeks after the first case was announced on March $2^{\text {nd }}, 2020$, Jordan decided to "flatten the curve" with a multi-pronged approach centered around mandatory physical distancing with a nationwide curfew, closed borders, and military patrols which was last seen last seen in the early 1990s [8, 10].

Early measures included the suspension of all international flights, the enforcement of strict curfews, restrictions on movement, and the closure of businesses, schools and universities. As the number of contagions remained low, restrictions were progressively relaxed over summer.

In parallel, the authorities launched a public communication and awareness campaign to inform the public on testing and treatment facilities and imposed social distancing measures and the use of masks.

In the fall, the sharp rise in COVID cases led the authorities to enforce local lockdowns. In early October, the Government re-instated a nationwide lockdown for Fridays and sometimes including Saturday suntil the end of 2020, and schools and universities were asked to switch to an online alternative until the end of the semester.

Some describe Jordan's initial measures to halt the spread of COVID-19 as the strictest in the region and among the strictest globally. Initially, these efforts have been successful in reaching the intended effects, flattening the curve with a limited number of infection cases through the end of August $[10,18]$ e.g. During March alone, Jordanian authorities arrested more than 1,600 persons for violating curfew. Table 3 Describes the Timeline of COVID-19 Policy Instruments in Jordan

Table 3. Timeline of COVID-19 Policy Instruments in Jordan.

\begin{tabular}{|c|c|c|l|l|}
\hline Date & Day & Year & & \multicolumn{1}{c}{ Event } \\
\hline 27 & February & 2020 & Begin screening for Covid-19 at airports. Two-week quarantine for all positive cases \\
\hline 2 & March & 2020 & First positive case announced \\
\hline 15 & March & 2020 & Schools closed \\
\hline 17 & March & 2020 & Borders closed \\
\hline 19 & March & 2020 & State of emergency (Defense orders) \\
\hline 21 & March & 2020 & The government implemented a nationwide 14-day general curfew, stopping all activities. \\
\hline 25 & March & 2020 & Citizens permitted to walk to stores and pharmacies \\
\hline 26 & March & 2020 & Impose punishments for breaching the defense orders (includes Fines, Jail etc..) \\
\hline 6 & April & 2020 & Factories located in industrial zones were allowed to resume operations. \\
\hline 21 & April & 2020 & Full curfew foe 48 hours \\
\hline 30 & April & 2020 & work partly resumed for selected sectors \\
\hline 4 & April & 2020 & Resuming most commercial activities \\
\hline & May & 2020 & Jordan lifted most lockdown measures and allowed most economic sectors to operate under \\
\hline
\end{tabular}




\begin{tabular}{|c|c|c|c|}
\hline Date & Day & Year & Event \\
\hline 6 & June & 2020 & $\begin{array}{l}\text { The authorities announced that transport between governorates would resume, night curfews } \\
\text { would be shortened, hotels and cafes would be allowed to re-open, along with sporting events } \\
\text { with no spectators }\end{array}$ \\
\hline 15 & July & 2020 & $\begin{array}{l}\text { The government also started organizing the return of Jordanians who were abroad since the } \\
\text { start of the crisis and had not been able to return given the interruption of international flights }\end{array}$ \\
\hline 13 & August & 2020 & Jordan closed its border with Syria due to virus concerns following an uptake? in new cases. \\
\hline 27 & August & 2020 & Friday curfews reimposed starting August 27 in Amman and Zarqa. \\
\hline 8 & September & 2020 & $\begin{array}{l}\text { Jordan re-opened airports for regular commercial flights with strict measures to contain the } \\
\text { pandemic*}\end{array}$ \\
\hline 15 & September & 2020 & $\begin{array}{l}\text { Defense Order 16, which introduced new measures designed to contain the pandemic (e.g.: } \\
\text { limits on social gatherings) and included strict penalties on people and businesses which } \\
\text { do not comply with health safety measures (incl. fines, establishment closure and potential } \\
\text { imprisonment). }\end{array}$ \\
\hline 18 & September & 2020 & $\begin{array}{l}\text { The government announced a prison sentence of up to one year for anyone organizing social } \\
\text { gatherings of more than } 20 \text { people }\end{array}$ \\
\hline 6 & October & 2020 & $\begin{array}{l}\text { the Government announced that a total lockdown would be imposed on all governorates on all } \\
\text { coming Fridays and Saturdays until further notice }\end{array}$ \\
\hline 20 & October & 2020 & $\begin{array}{l}\text { Total lockdowns would apply to all governorates only on Fridays, and introduced a daily curfews } \\
\text { from } 11 \mathrm{pm} \text { to } 6 \text { am for citizens and from } 10 \text { pm to } 6 \text { am for businesses across the country. } \\
\text { Schools and universities were also closed, and online education was re-instated until the end of } \\
\text { the first semester. }\end{array}$ \\
\hline 22 & October & 2020 & $\begin{array}{l}\text { the Government issued defense orders } 19 \text { and } 20 \text { which allowed Friday prayers while introducing } \\
\text { strict safety guidelines, restricted restaurants' operations to only } 50 \text { percent of capacity with } \\
\text { no more than six people per table, and introduced new fines on establishments and persons } \\
\text { whodid not abide by the defense orders rules. }\end{array}$ \\
\hline 3 & November & 2020 & $\begin{array}{l}\text { The Ministry of Health struck a deal with the Private Hospitals Association to allocate at least } \\
1,000 \text { beds and } 150 \text { ICU beds for COVID-19 patients who would be referred to private hospitals } \\
\text { by public hospitals. }\end{array}$ \\
\hline 11 & November & 2020 & Total lockdown would be implemented for 4 days. \\
\hline- & December & 2020 & the number of new weekly cases started to decline for the first time since \\
\hline 15 & December & 2020 & $\begin{array}{l}\text { The authorities announced that vaccination would start in } 2021 \text { Q1, with priority given to those } \\
\text { who are } 60 \text { years old or above, medical jobs or employees who contact the crowds and those } \\
\text { who suffer from chronic diseases. A first batch of } 200,000 \text { vaccines is expected to be delivered } \\
\text { in early } 2021 \text {. }\end{array}$ \\
\hline
\end{tabular}

The fight against COVID-19 in Jordan is led by the government through a collaborative multi-disciplinary team at the highest levels through the National Center for Security and Crises Management (NCSCM)

According to health statistics, Jordan has largely avoided the COVID-19 pandemic. As of early June 2020, there have only been 9 deaths in a population of 10 million [10]. Jordan implemented a strict clo- sure before the outbreak gained momentum. The country's swift lockdown was due to it being wellequipped to coerce the population, while being structurally ill-equipped to deal with a large outbreak.

\section{Jordan: "Epidemic (Epi) Curve" In Figure 18 \& 22.}


Figure 18: The weekly Jordan new cases and cumulative cases from Jan $1^{\text {st }}, 2020$ to Dec. $31^{\text {st }}, 2020$.

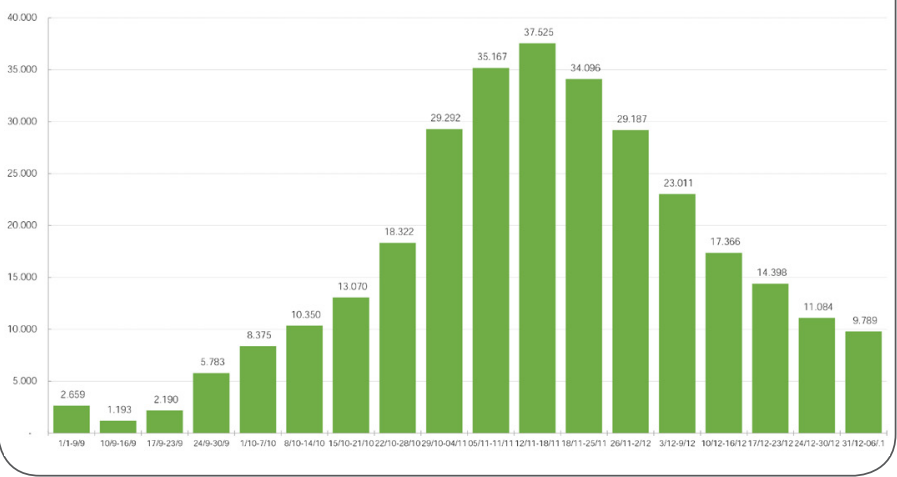

Figure 19: Weekly deaths from Jan 1st, 2020 to Dec. $31^{\text {st }}, 2020$.

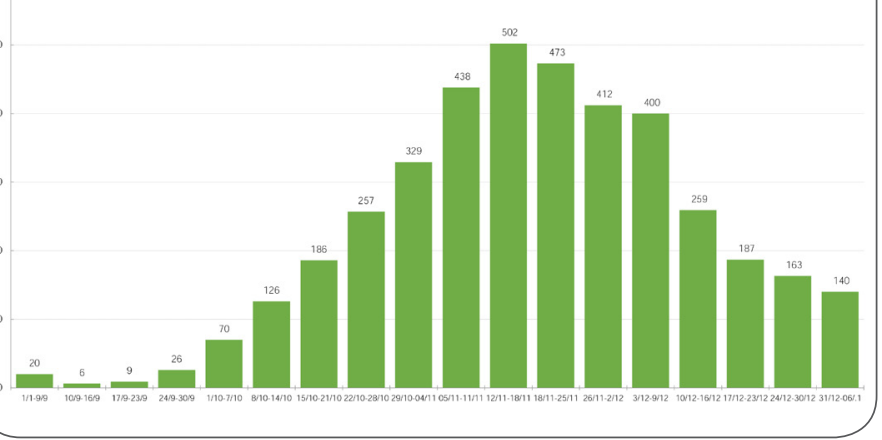

Figure 20: Weekly Positive ratio (\%) PCR testing from Jan $1^{\text {st }}, 2020$ to Dec. 31 ${ }^{\text {st }}, 2020$.

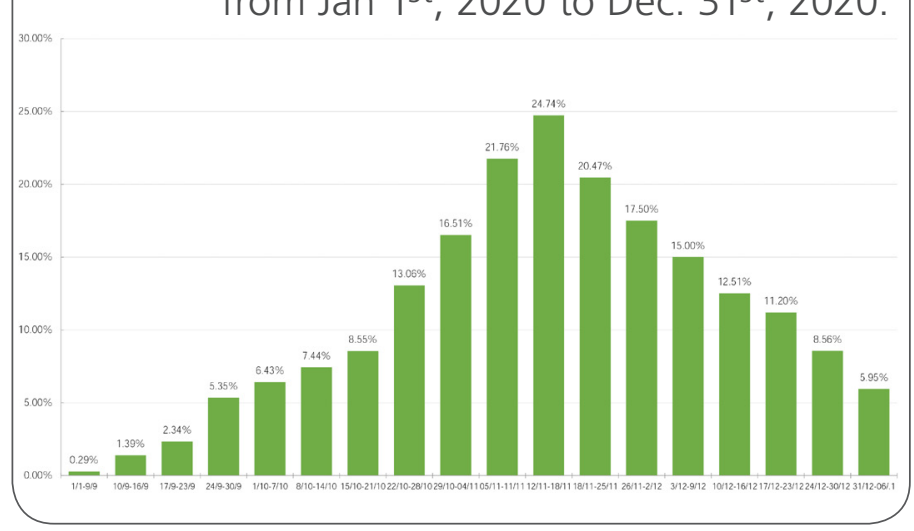

Figure 21: Jordan new cases per week and Jordan cumulative cases.

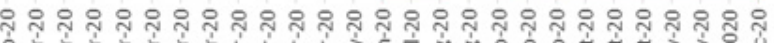

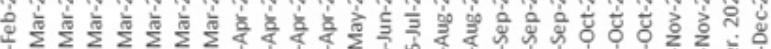

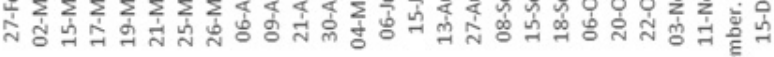

\section{Figure 22.}

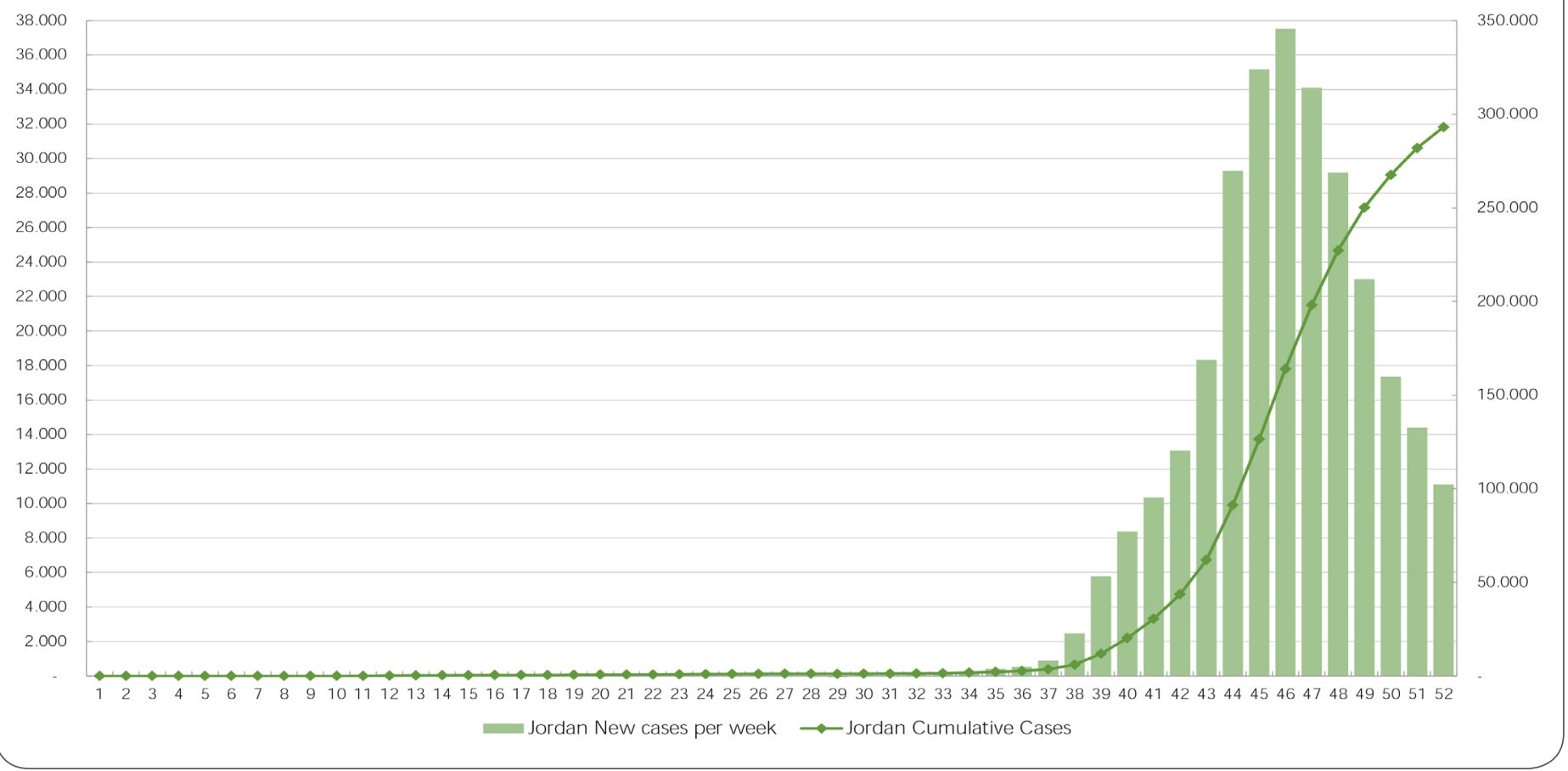




\section{Result and Discussion}

Arab countries is divided by large wealth disparities and regional conflicts, increasing risks to the COVID-19 pandemic that has no political or religious agenda. Despite varying levels of health system preparedness in these countries, early implementation of strict containment measures helped to limit the spread of SARS-CoV-2, therefore, Most Arab countries took some serious early steps to minimize the outbreak of COVID-19. In order to control the source of infection, the route of transmission and taking care of infected patients, including isolation of cases, contact tracing, social distancing, border closures, masking, hand and surface hygiene, and travel restrictions

Strict containment measures helped to limit the first wave and were gradually lifted from June onwards. But since then, the situation appears to be diverging: while the Gulf countries seem to have flattened the infection curve so far, the sanitary situation appears much more fragile elsewhere in the region.

In Jordan started from the early March of 2020, strict measures have been enforced in the general population to protect all the public from the COVID-19 Infection. The country has been under lockdown for several weeks, were schools and universities were closed, the means of transportation were stopped and only a few of them were functioning. Banks and commercial shops and malls were closed. The highest percentage of the population complied with these measures enforced fearing the strong pathogenicity of the virus. Due to these implemented measures, the epidemic was engulfed and we had very few new cases of the disease, in comparison with other European countries (Italy, Spain, Germany, UK and France) and definitely with the US also with Arab MENA countries as seen before. Where the new cases of the epidemic amounted in several thousands of carriers and victims.

\section{Do the policies of social isolation really work?}

The first case was reported in March 2, 2020, thus we have a considerable amount of available data to make a good analysis, we observed that the implementation of social distancing policies changed the initial exponential growth to a sub-exponential one. Finally, we consider the relaxation of such policies leads to a new wave of epidemic. From the previous charts, spikes in the number of new cases were noticed during the $2^{\text {nd }}$ week of November 2020 (The great outbreak)

This raises concerns about the behavior of SARSCoV-2 and transmission dynamics. The Jordanian government has implemented various measures that are aimed at providing the public with essential information and directions by reaching different age groups across the country through media channels, such as television, Internet, and COVID-19 emergency hotlines, as well as through the armed and security forces who provided support and assistance for the public. The prediction of the spread of the outbreak process is of great importance for future measures to be taken.

\section{Conclusion}

At this stage and the uncertain future scenarios, it is difficult to critically compare the effectiveness of various COVID-19 response strategies at different countries. However, during and after the battle of COVID-19, countries, including Jordan, must take more serious steps to strengthen and improve their healthcare system capacity in order to be well-prepared for such crises in the future. Finally, having a sufficient reservoir of medical devices and personal protective equipment as well as a backup of highly trained healthcare staff to serve in critical care units will be of great assistance and support to keep going during pandemics. Whilst COVID-19 epidemic paths for most countries are similar; as seen before, some countries do have flatter and less severe lines 
than others. Our analysis suggests that justification measures taken by a government at the very initial stage of a COVID-19 outbreak might significantly impact severity and to a less extent duration of the epidemic.

\section{References}

1. World Health Organization (WHO). Transmission of SARS-CoV-2: implications for infection prevention precautions. Scientific brief. Geneva: WHO; 9 July 2020. [Accessed on 14 October 2020.] Available from: https://www.who.int/news-room/ commentaries/detail/transmission-of-sarscov-2-implicationsfor-infection-preventionprecautions.

2. McAloon C, Collins Á, Hunt K, Barber A, Byrne AW, Butler F et al. Incubation period of COVID-19: a rapid systematic review and meta-analysis of observational research. BMJ Open. 2020;10(8). doi: https://doi.org/10.1136/bmjopen-2020-039652.

3. Rothan HA, Byrareddy SN. The epidemiology and pathogenesis of coronavirus disease (COVID-19) outbreak. J Autoimmun. 2020;109. doi: https://doi.org/10.1016/j.jaut.2020.102433.

4. Hu Y, Sun J, Dai Z, Deng H, Li X, Huang Q et al. Prevalence and severity of corona virus disease 2019 (COVID-19): A systematic review and meta-analysis. J Clin Virol. 2020; 127. doi: https:// doi.org/10.1016/j. jcv.2020.104371.

5. WHO. Report of the WHO-China Joint Mission on Coronavirus Disease 2019 (COVID-19). Geneva: WHO; 2020. [Accessed on 14 October 2020.] Available from: https://www.who.int/docs/ default-source/coronaviruse/who-china-joint-mission-oncovid19-final-report.pdf

6. Li Q, Guan X, Wu P, Wang X, Zhou L, Tong Y, et al. Early Transmission Dynamics in Wuhan, China, of Novel CoronavirusInfected Pneumonia. N Engl J Med. 2020; NEJM oa2001316.

7. Dorigatti I, Okell L, Cori A, Imai N, Baguelin M, Bhatia S, et al. Report 4: Severity of 2019- novel coronavirus (nCoV).

8. Worldometer. Coronavirus update (live). Accessed December 31, 2020. https://www.worldometers.info/coronavirus.

9. World Health Organization. The Global Health Observatory. Accessed May 5, 2020. https://www.who.int/data/gho

10. Jordanian Ministry of Health. COVID-19 in Jordan (2020). Available online at: https://corona.moh.gov.jo.
11. Monitoring and tracking the disease | CDC,USA https:// www.cdc.gov/coronavirus/2019-ncov/cases-updates/aboutepidemiology/monitoring-and-tracking.html.

12. Epidemic Curves (bu.edu, 2017) https://sphweb.bumc.bu.edu/ otlt/MPH.Modules/EP/EP713.

13. Interpretation of Epidemic (Epi) Curves during Ongoing Outbreak Investigations. US Centers for Disease Control and Prevention, 2015. https://www.cdc.gov/foodsafety/outbreaks/ investigating-outbreaks/epi-curve.

14. Dr Adil Ramzan; Epidemic-Definition-Types of EpidemicEpidemic Curves, medicotips.com, 2011.

15. Coronavirus Disease 2019 (COVID-19) Situation Reports. World Health Organization. https://www.who.int/emergencies/ diseases/novel-coronavirus-2019/situation.

16. Department of Statistics Jordan. Population Count. (2020). Available online at: http://dosweb.dos.gov.jo/ (accessed April 16, 2020).

17. Manjari Singh, "Jordan after COVID-19: From Crisis Adjustment to Crisis Management", The Washington Institute, Fikra Forum, April 15, 2020, https://www.washingtoninstitute.org/ fikraforum/view/Jordan-responseCOVID19-pandemic-MiddleEast.

\section{Publish in The International}

Arabic Journal of Antimicrobial Agents

The Journal is an open access peer-reviewed journal that publishes scientific papers about all aspects of antimicrobials. The journal will publish original research articles, reviews, brief reports and case reports dealing with basic and clinical antibacterial agents, antiviral, antiprotozoals, antituberculuous, antifungal and antihelminthes agents. All manuscripts must be prepared in English, and are subject to a rigorous and fair peer-review process. Accepted papers will immediately appear online. The journal aims to advance the knowledge, attitude and the research of chemotherapy in the Arabic world in cooperation with international, national scientific and public societies as well as research centers with similar aims and objectives. 